\title{
Practical Astronomy
}

Springer-Verlag London Ltd. 


\section{Other titles in this series}

Telescopes and Techniques (2nd Edn.) Chris Kitchin

The Art and Science of CCD Astronomy David Ratledge (Ed.)

The Observer's Year

Patrick Moore

Seeing Stars

Chris Kitchin and Robert W. Forrest

Photo-guide to the Constellations

Chris Kitchin

The Sun in Eclipse

Michael Maunder and Patrick Moore

Software and Data for Practical Astronomers David Ratledge

Amateur Telescope Making

Stephen F. Tonkin (Ed.)

Observing Meteors, Comets, Supernovae and other Transient Phenomena

Neil Bone

Astronomical Equipment for Amateurs Martin Mobberley

Transit: When Planets Cross the Sun Michael Maunder and Patrick Moore

Practical Astrophotography

Jeffrey R. Charles

Observing the Moon

Peter T. Wlasuk

Deep-Sky Observing

Steven R. Coe

AstroFAQs

Stephen Tonkin

The Deep-Sky Observer's Year

Grant Privett and Paul Parsons

Field Guide to the Deep Sky Objects

Mike Inglis

Choosing and Using a Schmidt-Cassegrain

Telescope

Rod Mollise
Astronomy with Small Telescopes

Stephen F. Tonkin (Ed.)

Solar Observing Techniques

Chris Kitchin

Observing the Planets

Peter T. Wlasuk

Light Pollution

Bob Mizon

Using the Meade ETX

Mike Weasner

Practical Amateur Spectroscopy

Stephen F. Tonkin (Ed.)

More Small Astronomical Observatories

Patrick Moore (Ed.)

Observer's Guide to Stellar Evolution

Mike Inglis

How to Observe the Sun Safely

Lee Macdonald

The Practical Astronomer's Deep-Sky

Companion

Jess K. Gilmour

Observing Comets

Nick James and Gerald North

Observing Variable Stars

Gerry A. Good

Visual Astronomy in the Suburbs

Antony Cooke

Astronomy of the Milky Way: The Observer's

Guide to the Northern and Southern Milky Way

(2 volumes)

Mike Inglis

The NexStar User's Guide

Michael W. Swanson

Observing Binary and Double Stars

Bob Argyle (Ed.)

Navigating the Night Sky

Guilherme de Almeida 


\section{Amateur Telescope Making}

Stephen F. Tonkin (Ed.) 


\section{Stephen F. Tonkin, BSc, PGCE}

Cover photograph: CCD image by Andy Saulietis, Danciger Telescope Group

British Library Cataloguing in Publication Data

Amateur telescope making. - (Practical astronomy)

1.Telescopes - Design and construction - Amateurs' manuals

I.Tonkin, Stephen F.

$681.4^{\prime} 123$

ISBN 978-1-85233-000-2

Library of Congress Cataloging-in-Publication Data

Amateur telescope making / Stephen F. Tonkin (ed.).

p. cm. - (Practical astronomy)

Includes bibliographical references and index.

ISBN 978-1-85233-000-2 ISBN 978-1-4471-0567-1 (eBook)

DOI 10.1007/978-1-4471-0567-1

1. Telescopes-Design and construction-Amateur's manuals.

I. Tonkin, Stephen F., 1950- ～. II. Series.

QB88.A622 1998

98-33566

$681^{\prime} .4123-\mathrm{dc} 21$

Apart from any fair dealing for the purposes of research or private study, or criticism or review, as permitted under the Copyright, Designs and Patents Act 1988, this publication may only be reproduced, stored or transmitted, in any form or by any means, with the prior permission in writing of the publishers, or in the case of reprographic reproduction in accordance with the terms of licences issued by the Copyright Licensing Agency. Enquiries concerning reproduction outside those terms should be sent to the publishers.

ISSN 1617-7185 Patrick Moore's Practical Astronomy Series ISBN 978-1-85233-000-2

(c) Springer-Verlag London 1999

Originally published by Springer-Verlag London Limited in 1999

5th printing 2004

The use of registered names, trademarks, etc. in this publication does not imply, even in the absence of a specific statement, that such names are exempt from the relevant laws and regulations and therefore free for general use.

The publisher makes no representation, express or implied, with regard to the accuracy of the information contained in this book and cannot accept any legal responsibility or liability for any errors or omissions that may be made.

Typeset by EXPO Holdings, Malaysia

Printed at the University Press, Cambridge

58/3830-54 Printed on acid-free paper SPIN 11007005 
We dedicate this book, with humility, to the memory of the late Tom Waineo. Tom epitomised the most laudable qualities of the amateur telescope maker, giving selflessly of his time and using his extensive experience and wisdom in order to help others. We hope that our efforts will help to keep Tom's star shining. 


\section{Contents}

Introduction

Stephen Tonkin ix

\section{Shoestring Telescopes}

1 A 6-inch $\mathrm{f} / 5$ Telescope Steven Lee ....................... 3

2 "Skinflint": A 15.5-inch f/4.8 Reflector Gil Stacy $\ldots \ldots \ldots \ldots \ldots \ldots \ldots \ldots . . \ldots \ldots$

3 An 80 mm RFT Refractor Stephen Tonkin .................. 31

\section{Specialised Telescopes}

4 Building A High-Contrast Planetary Newtonian

Gary Seronik .................... 41

5 A Collapsible Refractor Klaus-Peter Schröder ............... 53

6 The Construction of a Buchroeder Quad-Shiefspiegler Terry Platt ...

7 A Wright Camera Bratislav Curcic

8 A Ball-Scope: The Best Portable Telescope! Steven Lee ...................... 95

\section{Mounts}

9 Equatorial Platforms

Chuck Shaw 
10 A Computerized Dobsonian Mel Bartels ..................... 155

11 Parallelogram Binocular Mount Scott Wilson .................. 179

\section{Astrophotography}

12 A Better Barn Door Stephen Tonkin .................. 195

13 "Skypod": A Simple Sky-Tracker for Astrophotography E.G. Mason ..................... 209

14 Building and Using a Cookbook CCD Camera Al Kelly ....................... 225

15 A Telescope Controller for Synchronous Motors

David Johnson

\section{Appendices}

Appendix 1: Internet Resources ........... 249

Appendix 2: Contributors ............. 251

Appendix 3: References .............. 255

Appendix 4: Bibliography $\ldots \ldots \ldots \ldots \ldots \ldots 257$ 


\section{Introduction}

Over the last few decades the range of mass-produced equipment available to amateur astronomers has increased in both extent and capability, and decreased in real-term cost. Obvious examples of the enhanced capability of amateur equipment lie in CCD cameras and computer-controlled mounts. The CCD is said to increase the light-gathering power of a telescope by a factor of about a hundred; that is, it is possible to take images with an 8 in $(20 \mathrm{~cm})$ instrument that would previously have required an 80 in $(2 \mathrm{~m})$ telescope using photographic emulsion. Of course, the resolving power of the 8 in is not also increased! Computer control enables simplified finding of faint objects and, coupled with a CCD, can automatically guide the telescope during imaging. Where then, in this context, is the place for amateur telescope making (ATMing) and the basement tinkerer, the person Albert Ingalls referred to, in his Amateur Telescope Making trilogy, as the TN - the Telescope Nut?

Quite simply, the opportunities for TNs - who are now better known as ATMs (amateur telescope makers) - have also increased correspondingly, and their craft has developed far beyond what can legitimately be termed "basement tinkering". Richard Berry's CCD Camera Cookbook has resulted in the construction and use of hundreds of home-made CCD cameras, at a cost well below that of the commercially available instruments. As Al Kelly demonstrates (Chapter 14), making a Cookbook CCD is, while timeconsuming, not a particularly difficult task, and the resulting images easily rival those taken with the massproduced products. Similarly, the innovations of Mel Bartels and others (Chapter 10) have extended computer control to the most common ATM telescope, the Dobsonian-mounted Newtonian, again at a muchreduced cost compared with commercial offerings.

While cost reduction has always been one of the driving forces behind ATM, it is neither the only one 
nor the most powerful. However, there are still among us those who aim to make good astronomical kit at a shoestring cost, and there are several such examples in the first section of this book. You should understand that the costs are cut not by sacrificing optical quality, but usually by adapting free or low-cost items that were intended for another purpose. While we don't eschew good craftsmanship, we stand by the principle (or is it merely an excuse?) that telescopes are primarily for looking through, not looking at. As long as the telescope holds the optical components rigidly in collimation while excluding stray light from the eyepiece, and the mount is as steady as the Rock of Gibraltar, while permitting smooth movement about two axes of rotation, all else is optional.

More often, the ATMing impulse is a response to mass production. One of the consequences of this mass production is standardisation, as witnessed by the ubiquitous 8 in $(20 \mathrm{~cm})$ Schmidt-Cassegrain telescopes. If you want something non-standard, you are often left with two choices: either to forgo the cost advantage of mass production by having a one-off instrument specially made, or to make the instrument yourself. The section "Specialised Telescopes" shows how some ATMs have met this need. This is the realm where much innovation takes place, and some ATMs have found their developments to be so popular that they have gone into commercial production.

Another powerful stimulus to ATMing lies in human nature - some of us are inveterate tinkerers. If we buy a telescope, within days we find we have invalidated the warranty. A few days (or, in some severe cases, hours) later, the first modification is made and within a month or so the instrument bears little relation to the original product. Our workshops usually contain several telescopes, mostly in various states of dismantlement, and we are known in astronomical circles as people who spend more time tinkering with telescopes than actually using them. This ailment is probably incurable, but its cravings are certainly satisfied by ATMing!

Whatever the impulse that attracted you to this book, you will find a number of ways that it differs from most other books on the subject. The most obvious of these is that each chapter is written by someone who has, to some extent, become an expert in the realm his chapter covers and who has, in most cases, spent considerable time helping others to attain a similar level of expertise. Each contributor is 
someone with a proven ability to make equipment that works effectively, and many have devised creative ways of using common artefacts - this inventiveness will inspire you to do likewise. He is also someone who is willing to help you further, should the need arise. To this end, the publishers have dedicated a World Wide Web site to this book, via which you can contact any of the contributors to the book.

This linking to a web site also enables the book to be kept up to date. In particular, software is continuously under development, but the latest versions may be obtained on the web.

The multi-contributor nature of the book is a microcosm of another aspect of ATMing: that of mutual aid. Most ATMs are eager to share the experiential fruits of their work with others, and many of the international group of contributors to this book "met" on the Internet via the ATM Mailing List, which was established purely to facilitate this sharing. Many of us have had the privilege of being advised, via this medium, by experts in their field. Those of us who began our ATMing with no tutor but a book will appreciate the value of a resource that can be questioned when the need arises; the ATM Mailing List is just such a resource and is an excellent forum for sounding out any ideas that this book may inspire.

Another difference is that optical work is not specifically covered. There are several reasons for this. It requires an entire book to itself, and there are already several excellent publications on the subject available. While it is true that optical work is a craft that can be learned, there are relatively few excellent amateur opticians - like any other craft, it takes time and practice to achieve excellence. Consequently many, but by no means all, first amateur mirrors are of inferior quality and, unless you have a specific desire to develop the necessary skills, it often makes good sense to purchase optical components from a reputable source. There usually is little financial saving, if any, to be made by making a small primary mirror, although the skills so gained will prepare you for those specialised tasks where there are significant savings are to be made. Obviously, most specialised instruments require specialised optical components, and for these you may have no choice but to make them yourself. If this is the case, it is advisable to learn your skills on a "standard" mirror, such as a 6 in $(15 \mathrm{~cm}) \mathrm{f} / 8$ or an 8 in $(20 \mathrm{~cm}) \mathrm{f} / 7$, before attempting the specialised optical surfaces. 
Whether you decide to buy your optics or to make them yourself, it is essential to learn to test them. It is unfortunate but true that not all mass-produced optical components are of the quality that the maker claims for them, and it makes excellent sense to be able to evaluate them for yourself. In any case, you will need to test your finished telescope, whatever the source of the optical components.

The Bibliography lists several excellent books on optical design, work and testing.

In any book of this nature that has an international body of contributors, it is inevitable that there will be a "confusion" of units of measurement. Even in countries that still use non-metric measures, focal lengths, particularly of eyepieces, are usually expressed in millimetres. The style I have adopted is that the author's chosen system of units is given first, followed by an appropriate "translation", where this is possible, when the measurement is first used. I have attempted to render these as translations into standard sizes where this is appropriate. For example, $\frac{3}{4}$ in is almost exactly $19 \mathrm{~mm}$, but the nearest metric equivalent to $\frac{3}{4}$ in thick plywood is $18 \mathrm{~mm}$ thick. There are some instances where a sensible translation is not helpful, usually in relation to screw threads. For example, a tripod bush for a camera has a $\frac{1}{4}$ in UNC $\left(\frac{1}{4}\right.$ in 20 tpi) thread - there is no metric equivalent. In these instances, I have not given equivalents.

Finally, although detailed instructions are provided for many of the projects in this book, a hallmark of ATMing is creativity. Each project will perform well if it is made as the author made it, but most are capable of adaptation and development to your specific needs or to the materials you have available. Although the projects vary greatly in simplicity/difficulty of construction, most will fall within the capability of an ATM with a moderately well-equipped workshop and reasonable workshop skills. Whether you use this book as a manual or as a source of ideas that you will develop to meet your own particular requirements, I hope you will find it as stimulating to read and use as I have found it to compile. 